\title{
Paradoxical Hormonal and Behavioral Responses to Hypothyroid and Hyperthyroid States in the Wistar-Kyoto Rat
}

Eva E. Redei, Ph.D., Leah C. Solberg, LT/SNM, Joseph M. Kluczynski, M.A., and William P Pare, Ph.D.

Wistar-Kyoto (WKY) rats show endogenous depressive behavior that can be reversed by antidepressants. Given that WKYs exhibit decreased sensitivity to some antidepressants and treatment-resistant depressed patients often show hypothalamic-pituitary-thyroid (HPT) dysregulation, we examined the behavioral and HPT hormonal responses of WKYs to altered thyroid status. "Euthyroid" WKYs had elevated basal plasma TSH and $T_{3}$ levels as compared to Wistars. Hypothyroidism increased TSH levels more in WKYs than in Wistars and increased response latency in the open field test (OFT) of WKYs only. Administration of $T_{4}$ and $T_{3}$ suppressed plasma TSH equally in both strains.
Wistars responded to increased $T_{3}$ levels with decreased response latency and increased activity in the OFT, but increased immobility in the forced swim test. In contrast, $W K Y$ s responded only to the high $T_{3}$ levels with decreased response latency in the OFT. These results suggest the existence of a decreased central nervous system sensitivity to thyroid hormones in WKYs that could be related to their depressive behavior.

Neuropsychopharmacology 24:632-639, 2001]

(C) 2001 American College of Neuropsychopharmacology.

Published by Elseiver Science Inc.
KEY WORDS: $T_{3}$; Depression model; Open field test; Forced swim test; Strains

The Wistar-Kyoto (WKY) rat is the normotensive progenitor strain of the spontaneously hypertensive rat (SHR) that Okamoto and Aoki (1963) isolated from a strain of Wistar rats, the Wistar/Hokkaido rat. The WKY rat differs from the SHR not only with respect to

From the Northwestern University Medical School (EER,LCS), The Asher Center, Department of Psychiatry and Behavioral Sciences, Chicago, Illinois, USA GT; and Veterans Administration Medical Center d(JMK,WPP), Perry Point, Maryland, USA GT

Address correspondence to: Eva E. Redei, Ph.D., The Asher Center for the Study and Treatment of Depressive Disorders, Department of Psychiatry and Behavioral Sciences, Northwestern University Medical School, 303 E. Chicago Ave, Ward 9-198, Chicago, IL 60611. Tel.: (312) 908-1791; E-mail: e-redei@northwestern.edu

Received 15 March 2000; revised 19 September 2000; accepted 2 November 2000. resting blood pressure but it also displays smaller stress-induced increases in plasma cathecholamines (McCarty et al. 1987), heart rate, and blood pressure (LeDoux et al. 1982; Rettig et al. 1986; Knardahl and Hendley 1990). In contrast, WKYs show larger endocrine and behavioral responses to stress compared not only to SHRs but also to Wistars and several other rat strains (Pare and Redei 1995). Because most current animal models of depression are based on stress-induced behavioral deficits, it is no surprise that the WKY rat, which is endogenously hyperresponsive to stress, also shows endogenous depressive behavior (Pare and Redei 1995).

A large body of literature from different laboratories supports these findings. WKY rats show increased depressive and anxious behavior in a number of tests as compared to several inbred and outbred rat strains (Pare 1989; Pare 1992a; Tizabi et al. 1992; Castanon et al. 
1993; Pare 1993; Pare and Redei 1993a; Pare and Redei 1993b; Pare 1994; Armario et al. 1995; Pare and Redei 1995; Courvoisier et al. 1996; Lahmame and Armario 1996; Marti and Armario 1996; Berton et al. 1997; Lahmame et al. 1997; Lopez-Rubalcava and Lucki 2000). The fact that these animals show both depressive and anxious behavior mirrors human psychopathology where there is a substantial comorbidity of depression and anxiety disorders (Pini et al. 1997). Chronic treatment with tricyclic antidepressants (Pare 1992b; Lahmame et al. 1997) decreases depressive behavior of WKYs as measured by decreased immobility and increased struggling in the forced swim test. However, WKYs respond to tricyclic antidepressants administered subacutely with increased (Lopez-Rubalcava and Lucki 2000) or decreased (Lahmame and Armario 1996; Lahmame et al. 1997) sensitivity as compared to other strains and WKYs seem to have a blunted behavioral response to serotonergic drugs as well (Lopez-Rubalcava and Lucki 2000). This seemingly decreased sensitivity to antidepressants prompted Lahmame and his colleagues to suggest that the WKY rat may be a model of treatment resistant depression (Lahmame and Armario 1996; Lahmame et al. 1997).

In human treatment resistant depression, one of the most consistent findings is the high prevalence of subclinical hypothyroidism (Howland 1993; Lasser and Baldessarini 1997; Pies 1997; van Praag 1997). The clinical findings that $\mathrm{T}_{3}$ can augment the antidepressant response in antidepressant refractory depression (Joffe et al. 1995; Henley and Koehnle 1997) supports the hypothesis that subclinical hypothyroidism lowers the threshold of depression or enhances depressive symptoms, but is not sufficient, per se, to cause depression (Kirkegaard and Faber 1991; Haggerty et al. 1993).

Some animal studies have also shown that experimental hypothyroidism increases depressive behavior in the forced swim test (Kulikov et al. 1997) and that thyroid hormones have activity similar to antidepressants (Martin et al. 1985; Massol et al. 1989). Given that WKYs show endogenous depressive behavior with a purportedly decreased sensitivity to antidepressant treatment, we asked whether WKYs exhibit a dysregulation of the hypothalamic-pituitary-thyroid (HPT) axis. Therefore, we have altered the thyroid hormone milieu of WKY and Wistar rats toward the hypo- or hyperthyroid state and measured the hormonal and behavioral responses of these animals to the altered HPT status.

\section{METHODS}

\section{Animals}

Male Wistar-Kyoto (WKY, Harlan, 9 weeks old) and Wistar (Harlan, 9 weeks old) rats were housed two per cage in a climate-controlled facility with a 14/10 light dark cycle (lights on 07:00 h). Four separate studies were carried out. In the 6-propyl-thiouracil (PTU) study, WKY and Wistar rats were either fed rat chow and a daily prepared Kool-Aid solution ad libitum (control) or $0.05 \%$ PTU in Kool-Aid solution for 3 weeks as described previously (Rittenhouse and Redei 1997). We used the Kool-Aid solution, because it masked the taste of PTU sufficiently so that the animals were drinking normal amounts of liquid. In the thyroxine administration study $\left(\mathrm{T}_{4}\right.$ study), WKY and Wistar rats were either fed rat chow and water ad libitum (control) or $\mathrm{T}_{4}$ $(0.012 \%)$ in drinking water for 3 weeks as described previously (Rittenhouse and Redei 1997). In the $T_{3}$ study, WKY and Wistar rats were injected IP daily with either the high dose tri-iodothyronine $\left(\mathrm{T}_{3}, 50 \mu \mathrm{g} / 100 \mathrm{~g}\right.$ body weight) or vehicle saline for 2 weeks. This high dose of $T_{3}$ was shown to result in very high plasma $T_{3}$ levels (Dellovade et al. 1996). In the case of the thyroidectomy study (TX study), WKY and Wistar rats were sham-thyroidectomized or thyroidectomized by Harlan-Sprague-Dawley (Indianapolis, IN) and arrived 1 week post-thyroidectomy. They were fed rat chow and either water ad libitum (sham control) or 3\% calcium lactate in drinking water (thyroidectomized rats) for 3 weeks. Animals were first exposed to the open field test. Twenty-four hours later, they were exposed to the first day of the 2-day forced swim test (FST). Animals were killed by decapitation $4 \mathrm{~h}$ post-FST. Trunk blood was collected to measure plasma $\mathrm{T}_{4}, \mathrm{~T}_{3}$ and $\mathrm{TSH}$ levels.

\section{RIAs}

Thyroid-stimulating hormone (TSH) was measured as described before (Rittenhouse and Redei 1997); standards and specific antiserum were obtained from the National Hormone and Pituitary Agency (NIDDK, Baltimore, MD). Rat TSH RP-2 was used for the iodination and standards. The assay sensitivity was $1.0 \mathrm{pg} /$ tube with an intra-assay coefficient of variation of $10.5 \%$. RIAs for $\mathrm{T}_{3}$ and $\mathrm{T}_{4}$ were performed using ImmuChemcoated tubes purchased from ICN Pharmaceuticals (Costa Mesa, CA), following the recommended protocol provided with each kit. The sensitivity limits were $1.0 \mathrm{ng} /$ tube and $0.5 \mu \mathrm{g} /$ tube for $\mathrm{T}_{3}$ and $\mathrm{T}_{4}$, with intraassay coefficients of variation of 4.1 and $5.2 \%$, respectively.

\section{Forced Swim Test (FST)}

The FST, conducted as originally described by Porsolt et al.(1977), utilizes a glass water tank $30 \mathrm{~cm}$ in diameter and $45 \mathrm{~cm}$ tall with the water level $15 \mathrm{~cm}$ from the top and water temperature at $25^{\circ} \mathrm{C}$. Rats were individually placed in the water tank for $15 \mathrm{~min}$. Twenty-four hours later, rats were placed once more in the tank for a 5-min 
session, and time spent floating and climbing on tank wall were recorded.

\section{Open Field Test (OFT)}

Animals were placed in the center of a novel 15 in diameter open field arena for a 5-min test session. The floor was divided into quadrants for assessment of movement within the field. Illumination was approximately 160 lux. Open field behaviors were scored by a trained observer who was blind to the treatment conditions. The time to leave the entry segment (response latency, s), and the number of arena segments crossed (activity) were recorded.

\section{Statistical Analysis}

The data were analyzed by a two-factor analysis of variance (ANOVA) design with Strain (WKY vs. Wistar) as one factor, and Treatment (PTU, $\mathrm{T}_{4}, \mathrm{~T}_{3}$, Thyroidectomy vs. Control) as the second factor. The Tukey HSD test, with a $p<.05$, was used as a post-hoc test to locate significant differences between strain-treatment conditions. To address specific and relevant experimental questions, secondary statistical analyses were conducted in some instances where the ANOVA interaction term was not significant. To address these questions, a Student's $t$-test was applied to determine the existence of significant differences between strain-treatment conditions.

\section{RESULTS}

\section{HPT Activity}

$\boldsymbol{T}_{4}$. Control "euthyroid" WKY rats had plasma $\mathrm{T}_{4}$ levels that were slightly, but not significantly, lower as compared to control Wistars in the PTU, $\mathrm{T}_{4}$, and $\mathrm{T}_{3}$ treatment study but were significantly lower in the thyroidectomy study (strain: $\mathrm{F}[1,33]=13.8$, strain and treatment interaction: $\mathrm{F}=4.32$, Tukey, $p<.5$; Figure 1 ). Plasma $\mathrm{T}_{4}$ levels decreased significantly after both PTU treatment and thyroidectomy (treatment: PTU: F[1,27] = 271.3, $p<.01$; TX: F[1,33] = 155.7, $p<.01$ ). Plasma $\mathrm{T}_{4}$ levels remained significantly higher in WKY/PTU rats as compared to Wistar/PTU rats $(t[14]=6.56, p<$ .010). Plasma $T_{4}$ levels were not significantly different between the WKY and Wistar thyroidectomized rats. Thyroxine treatment increased plasma $\mathrm{T}_{4}$ levels significantly $(\mathrm{F}[1,28]=22.6, p<.01)$ by about $100 \%$ in both strains equally. Treatment with very high levels of $\mathrm{T}_{3}$ significantly reduced plasma $\mathrm{T}_{4}(\mathrm{~F}[1,28]=87.6, p<.01)$ in both strains equally.

$T_{3} T_{3}$ levels in general were significantly higher in WKYs as compared to Wistars in three of the four stud-

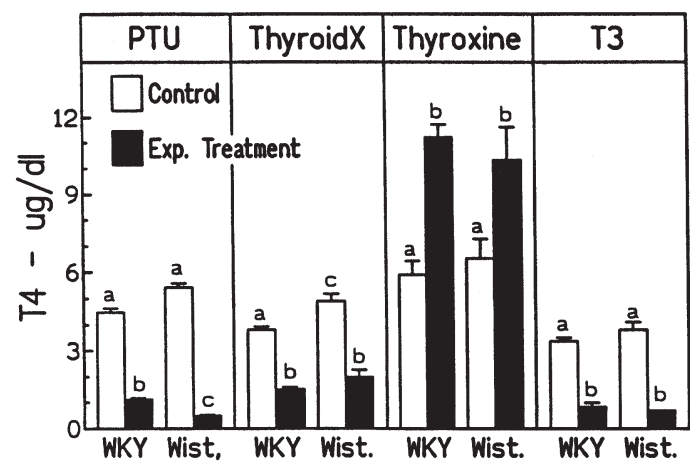

Figure 1. Plasma $T_{4}(\mu \mathrm{g} / \mathrm{dl})$ measures for Wistar-Kyoto (WKY) and Wistar rats. In the 6-propyl-thiouracil (PTU) study (first panel) WKY and Wistar rats were either presented with a Kool-Aid solution (Control) or a $0.05 \%$ PTU in Kool-Aid (Experiment Treatment) for 3 weeks. In the thyroidectomy (ThyroidX) study (second panel) WKY and Wistar rats were thyroidectomized (Experimental Treatment) or received sham operation (Control). In the Thyroxine study (third panel) WKY and Wistar rats were presented with either tap water (Control) or a $0.012 \% \mathrm{~T}_{4}$ solution (Experimental Treatment) for 3 weeks. In the $\mathrm{T}_{3}$ study (fourth panel) WKY and Wistar rats were injected daily with $50 \mu \mathrm{g} / 100 \mathrm{~g}$ body weight $\mathrm{T}_{3}$ (Experimental Treatment) or vehicle saline (Control) for 2 weeks. Values are means $( \pm \mathrm{SE})$ of data from 7-8 animals per group. Significant differences between Strain/Treatment groups were determined using the post-hoc Tukey honestly significant difference (HSD) test with a $p<.05$. Groups labeled with different letters are significantly different from each other.

ies (strain effect: PTU study: F[1,27] $=13.44, p<.01$; TX study: $\mathrm{F}[1,33]=22.7, p<.01 ; \mathrm{T}_{4}$ study: $\mathrm{F}[1,30]=9.8, p<$ .01 ; Figure 2). $\mathrm{T}_{3}$ levels were also significantly higher in WKY control rats as compared to Wistar controls in three studies (PTU study: $t[13]=3.39, p<.01$; TX study: $t[16]=6.54, p<.001 ; \mathrm{T}_{4}$ study: $t[11]=2.96, p<$ .05). Plasma $\mathrm{T}_{3}$ levels decreased significantly in both hypothyroid states (treatment: PTU: F[1,27] $=39.4, p<$ .01 ; TX: F[1,33] = 70.6, $p<.01$ ), similarly in both WKYs and Wistars. Thyroxine and $\mathrm{T}_{3}$ treatment increased plasma $\mathrm{T}_{3}$ significantly and equally in both strains $\left(\mathrm{T}_{4}\right.$ study: $\mathrm{F}[1,28]=87.8, p<.01 ; \mathrm{T}_{3}$ study: $\mathrm{F}[1,28]=324.0$, $\mathrm{p}<.01)$.

TSH. Despite the higher basal levels of $\mathrm{T}_{3}$, plasma TSH levels were significantly higher in control WKYs as compared to control Wistars in all four studies (strain and treatment interactions: PTU: F[1,27] $=11.4, p<$ .001 , Tukey $p<.05$; TX: F[1,33] $=8.5, p<.01$, Tukey, $p<$ $.05 ; \mathrm{T}_{4:} \mathrm{F}[1,33]=66.9, p<.001$, Tukey $p<.05 ; \mathrm{T}_{3:} \mathrm{F}[1,28]=$ 26.9, $p<.01$, Tukey $p<.05$, see Figure 3). As expected, all four treatments produced significant differences in plasma TSH. Plasma TSH levels rose in the hypothyroid states and were diminished in response to $\mathrm{T}_{4}$ (treatment effect: PTU study: $\mathrm{F}[1,23]=139.6 p<.01$; $\mathrm{TX}$ 


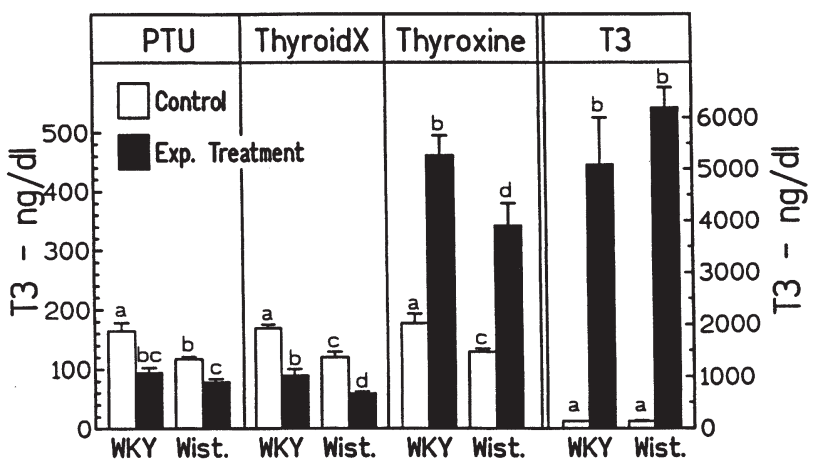

Figure 2. Plasma $T_{3}(\mathrm{ng} / \mathrm{dl})$ values for $\mathrm{WKY}$ and Wistar rats assigned to either the Control or Experimental Treatments in the four studies outlined in Figure 1. Values are means $( \pm \mathrm{SE})$. Groups labeled with different letters are significantly different from each other, $p<.05$.

study: $\mathrm{F}[1,30]=134.1 p<.01 ; \mathrm{T}_{4}$ study: $\mathrm{F}[1,28]=564.9$, $p<.01 ; \mathrm{T}_{3}$ study: $\left.\mathrm{F}[1,28]=58.2, p<.01\right)$, but TSH values were significantly $(p<.05)$ higher in WKY/hypothyroid animals compared to hypothyroid Wistars.

\section{Behavioral Measures}

Open Field Test. Response latency was significantly higher and activity significantly lower in control WKYs as compared to control Wistars in all four studies. There were significant strain effects for response latency: (PTU study: $\mathrm{F}[1,27]=10.2, p<.01 ; \mathrm{TX}$ study: $\mathrm{F}[1,33]=$ $7.54, p<.01 ; \mathrm{T}_{4}$ study: $\mathrm{F}[1,28]=82.3, p<.001 ; \mathrm{T}_{3}$ study: $\mathrm{F}[1,28]=64.9, p<.01$; see Figure 4 top panel), and for activity: (PTU study: $\mathrm{F}[1,27]=145.0, p<.001$; $\mathrm{TX}$ study: $\mathrm{F}[1,33]=155.9, p<.001 ; \mathrm{T}_{4}$ study: $\mathrm{F}[1,28]=$ 106.4, $p<.001 ; \mathrm{T}_{3}$ study: $\mathrm{F}[1,28]=98.4, p<.01$, see Figure 4 bottom panel). The response latency and activity values of control Wistars and WKYs differed among the PTU, TX, and the $T_{4} T_{3}$ studies, although the relative

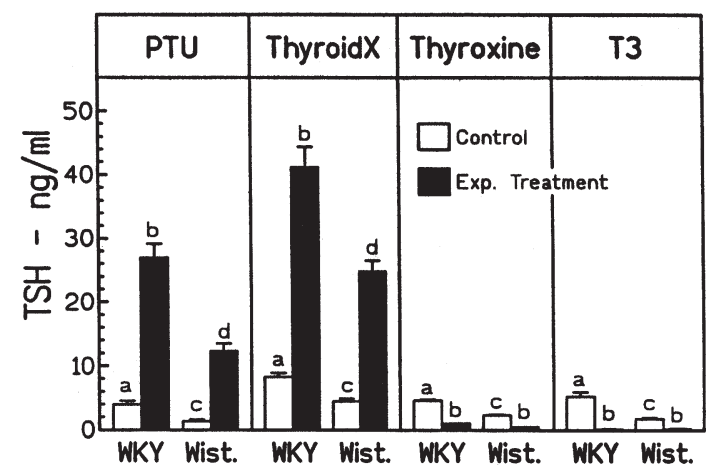

Figure 3. Plasma TSH (ng/ml) values for WKY and Wistar rats in the four studies as outlined in Figure 1. Groups labeled with different letters are significantly different from each other, $p<.05$.

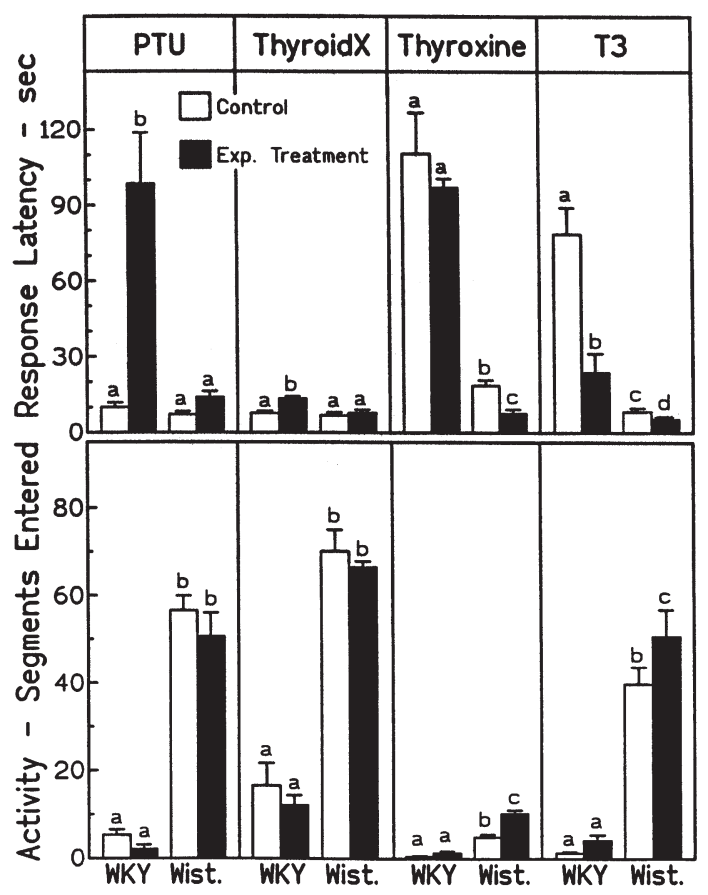

Figure 4. Open field test behaviors recorded from the PTU, ThyroidX, Thyroxine, and $\mathrm{T}_{3}$ experiments. The top panel illustrates the mean $( \pm S E)$ response latency scores (s). The bottom panel illustrates the mean $( \pm S E)$ activity scores. Groups labeled with different letters are significantly different from each other as detected by the post-hoc Tukey HSD test, $p<.05$.

differences between the strains were the same. This discrepancy in the values could be caused by different experimenters in these studies or by differences between shipments of WKYs (Kurtz and Morris 1987; Kurtz et al. 1989; Pare and Kluczynski 1997).

Response latency increased significantly in both hypothyroid states (treatment: PTU: F[1,27] $=12.1, p<.01$ and TX: F[1,33] = 8.75, $p<.01$ ), but not equally in WKYs and Wistars. The effect of hypothyroidism was dramatic and significant only in WKYs and not in Wistars (strain and treatment interactions: PTU: F[1,27] = 8.9, $p<.01$; TX: F[1,33] = 4.3, $p<.05)$. Activity did not change significantly in response to hypothyroid states in either strain. In contrast, treatment with $\mathrm{T}_{4}$ significantly decreased response latency (treatment: $F[1,34]=4.54$; interaction: $\mathrm{F}=4.1$, Tukey $p<.05)$ and increased activity (treatment: $\mathrm{F}[1,28]=23.3$, interaction: $\mathrm{F}=12.4$, Tukey $p<$ $.05)$, although only in Wistars. Treatment with $\mathrm{T}_{3}$ decreased response latency in both WKYs and Wistars (treatment: $\mathrm{F}[1,18]=25.3$, interaction: $\mathrm{F}=4.4$, Tukey $p<$ $.05)$, but it increased activity significantly only in Wistars(interaction: $\mathrm{F}[1,28]=5.2, p<.05$, Tukey $p<.01$ ).

Forced Swim Test. WKYs showed significantly increased floating and decreased climbing times in the forced swim test as compared to Wistars, confirming 
previous results (strain effects for floating: PTU study: $\mathrm{F}[1,27]=140.3, p<.01 ; \mathrm{TX}$ study: $\mathrm{F}[1,33]=85.3, p<$ $.01 ; \mathrm{T}_{4}$ study: $\mathrm{F}[1,28]=41.5, p<.01 ; \mathrm{T}_{3}$ study: $\mathrm{F}[1,28]=$ 78.3, $p<.01$, see Figure 5 top panel; strain effects for climbing: PTU study: F[1,27] = 255.8, $p<.01$; TX study: $\mathrm{F}[1,33]=89.1, p<.01 ; \mathrm{T}_{4}$ study: $\mathrm{F}[1,28]=55.2, p<.01$; $\mathrm{T}_{3}$ study: $\mathrm{F}[1,28]=89.6, p<.01$, see Figure 5 bottom panel).[FIG. 5] There was no effect of the hypothyroid states on the floating or climbing times in either strain. As control WKYs already approached maximum immobility, hyperthyroid state affected only the Wistars with significantly increased immobility and decreased climbing in the forced swim test (strain and treatment interaction for floating: $\mathrm{T}_{4}$ study: $\mathrm{F}[1,28]=10.8, p<.01$, Tukey $p<.05 ; \mathrm{T}_{3}$ study: $\mathrm{F}[1,28]=12.7, p<.01$, Tukey $p<$ .01; Strain and Treatment interaction for climbing: $\mathrm{T}_{4}$ study: $\mathrm{F}[1,28]=13.6, p<.01$; Tukey $p<.05 ; \mathrm{T}_{3}$ study: $\mathrm{F}[1,28]=15.1, p<.01$, Tukey $p<.05)$.

\section{Correlation Between Behavioral and Hormonal Measures}

The behavioral and hormonal measures of WKY and Wistar rats from all four studies were correlated separately for all control and all treated groups. We chose to explore correlation separately, because we assumed

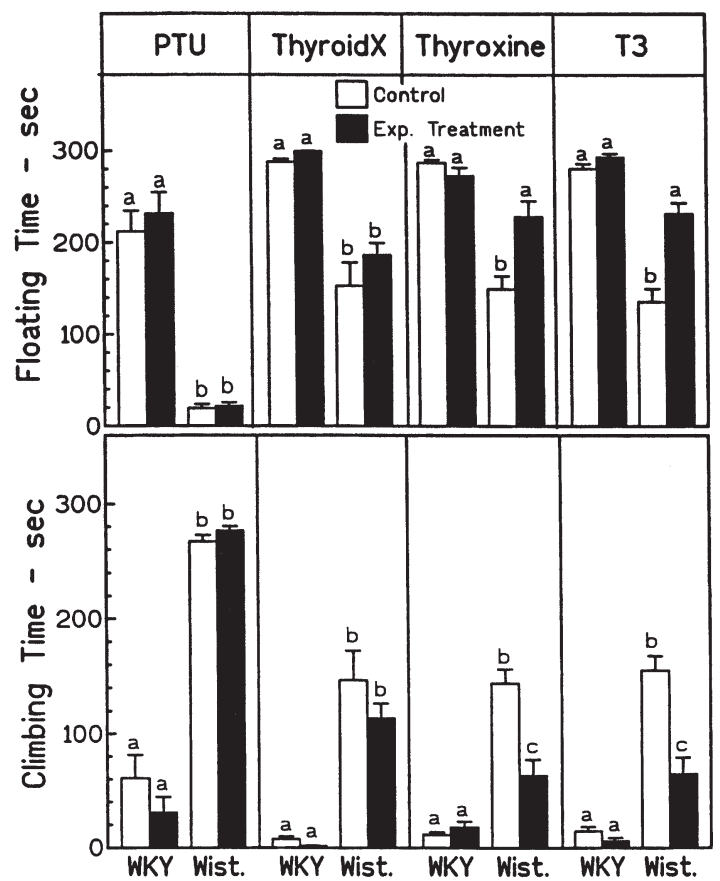

Figure 5. Forced swim behaviors on the second day of the swim test in the PTU, ThyroidX, Thyroxine, and $\mathrm{T}_{3}$ experiments. The top panel illustrates the mean ( \pm SE) floating (s). The bottom panel illustrates the mean $( \pm S E$ ) climbing time (s). Groups labeled with different letters are significantly different from each other as detected by the Tukey HSD test, $p<.05$. that the interaction between basal levels of thyroid hormones, TSH, and behavior differs from those where hormone levels are manipulated. This assumption is confirmed by the lack of correlation between basal levels of $\mathrm{T}_{4}, \mathrm{~T}_{3}$, and TSH in both strains; whereas, there was a very high correlation among these measures after treatment.

Control Wistars, but not WKYs, showed a significant positive correlation between response latency in the OFT and plasma $\mathrm{T}_{4}(\mathrm{r}=0.34, n=32)$ that was confirmed by the significant negative correlation between activity and $\mathrm{T}_{4}(\mathrm{r}=-0.30)$. Treated Wistars, but not WKYs, also showed significant positive correlation of floating with $\mathrm{T}_{4}(\mathrm{r}=0.42, n=34)$ and $\mathrm{T}_{3}(\mathrm{r}=0.41)$ and a significant negative correlation between activity and $\mathrm{T}_{4}$ $(r=-0.67 ; n=34)$. The only correlation that did not differ between the strains showed positive correlation between activity in the OFT and plasma TSH (Wistar control: $\mathrm{r}=0.34$; treatment: $\mathrm{r}=0.56$; WKY control: $\mathrm{r}=$ 0.30 ; treatment: $r=0.48$ ).

\section{DISCUSSION}

The results of these studies confirm previous notions that changes in thyroid hormonal milieu can affect behavior in the adult animal. The effect of altered thyroid hormone status on the depressive behavior in the forced swim test and on the exploratory/anxious behavior in the open field test is different. Furthermore, the degree by which thyroid hormones affect these behaviors differs between WKYs and Wistars presumably because of decreased central nervous system sensitivity to thyroid hormones in the WKYs that show increased HPT function in the basal "euthyroid" state.

Control WKYs showed significantly higher plasma TSH and $\mathrm{T}_{3}$ levels as compared to Wistars. Because both TSH and $\mathrm{T}_{3}$ were elevated, it is likely that $\mathrm{T}_{3}$ levels higher than the already elevated basal $\mathrm{T}_{3}$ are necessary in WKYs for efficiently regulating basal TSH levels. This suggestion was supported by the much greater increase of plasma TSH observed in WKYs as compared to Wistars in response to the two different hypothyroid states. Furthermore, hypothyroid states exaggerating the relative lack of $\mathrm{T}_{3}$ increased the anxiety-related response latency behavior in the OFT in WKYs but not in Wistars. Thus, the hypothyroid state-induced decrease in thyroid hormone levels affected the behavior of WKYs more than those of Wistars. Conversely, thyroxine administration increased plasma $\mathrm{T}_{3}$ levels sufficiently for Wistars, but not for WKYs, to affect both OFT and FST behavior. Floating could not be affected by hyperthyroid status in WKYs because of a ceiling effect, but response latency in the OFT could have been decreased by $\mathrm{T}_{4}$ if sensitivity to thyroid hormones is the same in WKYs and Wistars. $T_{3}$ administration led to 10 -fold higher plasma $\mathrm{T}_{3}$ levels 
than those achieved after administration of thyroxine, and these high $\mathrm{T}_{3}$ levels were sufficient to affect WKYs' behavior as well in the OFT. Thus, it indeed seems that WKYs exhibit decreased behavioral sensitivity to thyroid hormones as compared to Wistars.

Elevated basal TSH in the presence of elevated $\mathrm{T}_{3}$ could be caused by increased hypothalamic TRH stimulation or decreased feedback inhibition. The primary regulator of plasma TSH levels is thought to be negative feedback when thyroid hormone receptors are functional, as was illustrated in the TRH knock-out mice (Yamada et al. 1997) where plasma TSH was elevated. Further arguing for the lack of involvement of TRH in the elevated TSH levels of WKYs, we found no difference in hypothalamic prepro-TRH mRNA levels between WKY and Wistar rats (Suzuki et al. in press), although TRH peptide levels were not measured.

Decreased feedback inhibition could be attributed to decreased availability of $T_{3}$ at the sites of feedback inhibition. $\mathrm{T}_{4}$ is converted into $\mathrm{T}_{3}$ by type II 5 '-iodothyronine deiodinase ( $5^{\prime} \mathrm{D}$-II) in the brain and pituitary. Because TSH in WKYs was suppressed by $\mathrm{T}_{4}$ treatment, but no behavioral response was observed, $5^{\prime} \mathrm{D}-\mathrm{II}$ alterations are not likely to cause the lack of central responsiveness to $\mathrm{T}_{4}$ in WKYs. Furthermore, $5^{\prime} \mathrm{D}$-II expression is increased in response to stress (Baumgartner et al. 1998) that is likely to be glucocorticoid-mediated, because a glucocorticoid responsive element has been found in the promoter region of $5^{\prime}$ D-II. Because the diurnal CORT peak is increased and prolonged in WKYs (Solberg et al. in press), 5' D-II could be high in both the hypothalamus and the pituitary of the stress-hyper-responsive WKY leading to normal to high levels of local $\mathrm{T}_{3}$. However, neither these normal to high levels of endogenous $T_{3}$ nor the $T_{4}$ administration-induced elevated $\mathrm{T}_{3}$ affected behavior; suggesting decreased central sensitivity to thyroid hormones in the WKYs. Further support of this suggestion is that WKYs showed no correlation between behavioral measures and thyroid hormones; whereas, floating correlated positively, and activity in the OFT correlated negatively with $\mathrm{T}_{4}$ and $\mathrm{T}_{3}$ in Wistars. Therefore, WKYs' behavior has no simple causal relationship to their plasma thyroid hormone levels.

The present findings, of a positive correlation between $\mathrm{T}_{3}, \mathrm{~T}_{4}$ and immobility in the FST in Wistars, are the opposite of some previous observations, but agrees with others. Experimental hypothyroidism has been shown to increase depressive behavior in the forced swim test (Kulikov et al. 1997), and thyroid hormones were suggested to have activity similar to antidepressants (Martin et al. 1985; Massol et al. 1989). In contrast, hypothyroidism was shown to attenuate the acquisition of the immobile response: it decreased immobility at the second day of the FST (Jefferys and Funder 1989). This decrease was reversed by administration of $T_{4}$ up to $2 \mathrm{~h}$ after the initial test. Using the learned helplessness paradigm and identical PTU treatment, Martin et al. (1987) could not detect a hypothyroidism-induced facilitation of helpless behavior, although Brochet et al. (1987) found that $\mathrm{T}_{3}$ potentiated the effects of antidepressants in eliminating depressive-like behavior (escape deficit in the shuttle box). In this and previous studies, peripheral thyroid indices do not seem to determine (Martin et al. 1987) the effect of hypo- or hyperthyroidism on behavior, rather the behavioral effect is dependent on brain thyroid hormone levels or efficacy and/or some other thyroid hormone-induced factor(s) beyond the peripheral thyroid hormone status of the subject. Thus, the contradictory results obtained previously and in the present study could be related to higher or lower brain thyroid hormone levels, and, therefore, different thyroid hormone receptor occupancy achieved in these strains of animals.

It has been shown that thyroidectomy increases $\mathrm{TR} \beta_{1}$ immunoreactivity in specific brain regions that include the caudate-putamen, habenular nucleus, and the dorsal lateral septum (Nobrega et al. 1997). Recently, we have demonstrated that hypothyroidism, induced by PTU, decreases TR $\alpha_{1}$, and $\beta_{1}$ expression in the hippocampus but increases $\mathrm{TR} \alpha_{1}$ and $\beta_{1}$ expression in the hypothalamus (Pawlyk et al. 1996). TR $\beta_{2}$ has also been found in different brain regions ( $\mathrm{Li}$ and Boyages 1996). However, little is known of the effect of thyroid hormone milieu on TR expression in brain regions that have been suggested to be involved in the OFT or FST behavior; namely, the amygdala (Werka et al. 1978; Shimazoe et al. 1988; Nieminen et al. 1992) and the prefrontal cortex (Burns et al. 1996; Zangen et al. 1999). Thus, distribution of the TR isoforms and their regionspecific response to changes in thyroid hormone milieu could be responsible for the differential effects of thyroid hormones on behavioral measures in the OFT and the FST, such as decreased activity (swimming) in the Wistars in the FST but increased activity (segments entered) in the OFT in response to hyperthyroid states. Alternatively, recently it has been suggested, for the transcriptional induction of $\mathrm{RC} 3 /$ neurogranin by $\mathrm{T}_{3}$, that the brain region-specific differential sensitivity to $\mathrm{T}_{3}$ was not related to the differential expression of TR isoforms (Guadano-Ferraz et al. 1997). The authors suggest that cell sensitivity to thyroid hormones in the brain depend upon $\mathrm{T}_{3}$ receptor associated factors.

The findings of the current study suggest that there may exist a decreased sensitivity to thyroid hormones in the central nervous system of the WKYs. Although WKYs respond to hypo-and hyperthyroid state with the appropriate changes in plasma TSH, they show a basal dysregulation of the HPT activity and only respond to very high levels of $\mathrm{T}_{3}$ behaviorally. The possibility of a dysfunction of thyroid hormone receptors in the brain of the WKYs is currently being investigated. 


\section{REFERENCES}

Armario A, Gavalda A, Marti J (1995): Comparison of the behavioral and endocrine response to forced swimming stress in five inbred strains of rats. Psychoneuroendocrinology 20(8):879-890

Baumgartner A, Hiedra L, Pinna G, Eravci M, Prengel H, Meinhold H (1998): Rat brain type II 5'-iodothyronine deiodinase activity is extremely sensitive to stress. J Neurochem 71(2):817-826

Berton O, Ramos A, Chaouloff F, Mormede P (1997): Behavioral reactivity to social and nonsocial stimulations: A multivariate analysis of six inbred rat strains. Behav Genet 27:155-166

Brochet DM, Martin P, Soubrie P, Simon P (1987): Tri-iodothyronine potentiation of antidepressant-induced reversal of learned helplessness in rats. Psychiat Res 21:267275

Burns LH, Annett L, Kelley AE, Everitt BJ, Robbins TW (1996): Effects of lesions to amygdala, ventral subiculum, medial prefrontal cortex, and nucleus accumbens on the reaction to novelty: Implication for limbic-striatal interactions. Behav Neurosci 110(1):60-73

Castanon N, Hendley ED, Fan XM, Mormede P (1993): Psychoneuroendocrine profile associated with hypertension or hyperactivity in spontaneously hypertensive rats. Am J Physiol 265:R1304-R1310

Courvoisier H, Moisan MP, Sarrieau A, Hendley ED, Mormede P (1996): Behavioral and neuroendocrine reactivity to stress in the WKHA/WKY inbred rat strains: A multifactorial and genetic analysis. Brain Res 743(1-2):77-85

Dellovade TL, Zhu Y, Krey L, Pfaff DW (1996): Thyroid hormone and estrogen interact to regulate behavior. Neurobiology 93:12581-12586

Guadano-Ferraz A, Escamez MJ, Morte B, Vargiu P, Bernal J (1997): Transcriptional induction of RC3/neurogranin by thyroid hormone: Differential neuronal sensitivity is not correlated with thyroid hormone receptor distribution in the brain. Brain Res Mol Brain Res 49(1-2):37-44

Haggerty Jr JJ, Stern RA, Mason GA, Beckwith J, Morey CE, Prange Jr AJ (1993): Subclinical hypothyroidism: A modifiable risk factor for depression? Am J Psychiat 150(3):508-510

Henley WN, Koehnle TJ (1997): Thyroid hormones and the treatment of depression: An examination of basic hormonal actions in the mature mammalian brain. Synapse 27:36-44

Howland RH (1993): Thyroid dysfunction in refractory depression: Implications for pathophysiology and treatment. J Clin Psychiat 54(2):47-54

Jefferys D, Funder JW (1989): Thyroid hormones and the acquisition and retention of behavioral responses. Endocrinology 123(2):1103-1105

Joffe RT, Sokolov STH, Singer W (1995): Thyroid hormone treatment of depression. Thyroid 5:235-239

Kirkegaard C, Faber J (1991): Free thyroxine and 3,3',5' -triiodothyronine levels in cerebrospinal fluid in patients with endogenous depression. Acta Endocrinol 124:166171
Knardahl S, Hendley ED (1990): Association between cardiovascular reactivity to stress and hypertension or behavior. Am J Physiol 259:H248-H257

Kulikov A, Torresani J, Jenningros R (1997): Experimental hypothyroidism increases immobility in rats in the forced swim paradigm. Neurosci Lett 234:111-114

Kurtz TW, Montano M, Chan L, Kabra P (1989): Molecular evidence of genetic heterogeneity in Wistar-Kyoto rats: Implications for research with the spontaneously hypertensive rat. Hypertension 13(2):188-192

Kurtz TW, Morris RCJ (1987): Biological variability in Wistar-Kyoto rats: Implications for research with the spontaneously hypertensive rat. Hypertension 10(1): 127-131

Lahmame A, Armario A (1996): Differential responsiveness of inbred strains of rats to antidepressants in the forced swimming test: Are Wistar-Kyoto rats an animal model of subsensitivity to antidepressants? Psychopharmacology 123:191-198

Lahmame A, del Arco C, Pazos A, Yritia M, Armario A (1997): Are Wistar-Kyoto rats a genetic animal model of depression resistant to antidepressants? Eur J Pharmacol 337:115-123

Lasser RA, Baldessarini RJ (1997): Thyroid hormones in depressive disorders: A reappraisal of clinical utility. Harvard Rev Psychiat 4:291-305

LeDoux JE, Sakaguchi A, Reis DJ (1982): Behaviorally selective cardiovascular hyper-reactivity in spontaneously hypertensive rats. Hypertension 4:853-863

Li M, Boyages SC (1996): Detection of extended distribution of beta2-thyroid hormone receptor messenger ribonucleic acid (RNA) in adult rat brain using complementary RNA in situ hybridization histochemistry. Endocrinology 137(4):1272-1275

Lopez-Rubalcava C, Lucki I (2000): Strain differences in the behavioral effects of antidepressant drugs in the rat forced swimming test. Neuropsychopharmacology 22(2):191-199

Marti J, Armario A (1996): Forced swimming behavior is not related to the corticosterone levels achieved in the test: A study with four inbred rats strains. Physiol Behav 59:369-373

Martin P, Brochet D, Soubrie P, Belon JP (1985): Triiodothyronine-induced reversal of learned helplessness in rats. Biol Psychiat 20:1023-1025

Martin P, Massol J, Belon JP, Gaudel G, Soubrie P (1987): Thyroid function and reversal by antidepressant drugs of depressive-like behavior (escape deficits) in rats. Neuropsychobiology 18:21-26

Massol J, Martin P, Brochet D, Belon JP, Puech AJ (1989): Are antidepressant-like effects of triiodothyronine (T3) in rodents related to an hyperthyroid state? Prog Neuropsychopharmacol Biol Psychiat 13:749-764

McCarty R, Chiueh CC, Kopin IJ (1987): Spontaneously hypertensive rats: Adrenergic hyper-responsivity to anticipation of electric shock. Behav Biol 23:180-188

Nieminen SA, Sirvio J, Teittinen K, Pitkanen A, Airaksinen MM, Riekkinen P (1992): Amygdala kindling increased fear-response, but did not impair spatial memory in rats. Physiol Behav 51(4):845-849 
Nobrega JN, Raymond R, Puymirat J, Belej T, Joffe RT (1997): Regional changes in B1 thyroid hormone receptor immunoreactivity in rat brain after thyroidectomy. Brain Res 761:161-164

Okamoto K, Aoki K (1963): Development of a strain of spontaneously hypertensive rats. Japan Circ J 27:282-293

Pare WP (1989): Stress ulcer susceptibility and depression in Wistar-Kyoto (WKY) rats. Physiol Behav 46(6):993-998

Pare WP (1992a): Learning behavior, escape behavior, and depression in an ulcer susceptible rat strain. Integ Physiol Behav Sci 27(2):130-141

Pare WP (1992b): The performance of Wistar-Kyoto WKY rats on three tests of emotional behavior. Physiol Behav 51:1051-1056

Pare WP (1993): Passive-avoidance behavior in WistarKyoto (WKY), Wistar, and Fisher-344 rats. Physiol Behav 54(5):845-852

Pare WP (1994): Open field, learned helplessness, conditioned defensive burying, and forced swim tests in WKY rats. Physiol Behav 55(3):433-439

Pare WP, Kluczynski J (1997): Differences in the stress response of Wistar-Kyoto (WKY) rats from different vendors. Physiol Behav 62(3):643-648

Pare WP, Redei E (1993a): Depressive behavior and stress ulcer in Wistar-Kyoto rats. J Physiol Paris 87(4):229-238

Pare WP, Redei E (1993b): Sex differences and stress response of WKY rats. Physiol Behav 54(6):1179-1185

Pare WP, Redei E (1995): A biobehavioral profile of an ulcersusceptible rat strain. In Szabo S, Y Tache (eds), Neuroendocrinology of Gastrointestinal Ulceration. New York, Plenum Press, pp 201-208

Pawlyk AC, Rittenhouse PA, Redei E, Whybrow PC, TejaniButt SM (1996): Hypothyroid state alters expression of mRNAs encoding thyroid hormone receptor subtypes in rat brains: permissive role of adrenal. Program of the 10th International Congress on Endocrinology :650

Pies RW (1997): The diagnosis and treatment of subclinical hypothyroid states in depressed patients. Gen Hosp Psychiat 19:344-354

Pini S, Cassano GB, Simonini E, Savino M, Russo A, Montgomery SA (1997): Prevalence of anxiety disorders comorbidity in bipolar depression, unipolar depression, and dysthymia. J Affect Disord 42:145-153

Porsolt RD, Le Pichon M, Jalfre M (1977): Depression: A new animal model sensitive to antidepressant treatments. Nature 266(5604):730-732

Rettig R, Geyer MA, Printz MP (1986): Cardiovascular concomitants of tactile and acoustic startle responses in spontaneously hypertensive and normotensive rats. Physiol Behav 36:1123-1128

Rittenhouse PA, Redei E (1997): Thyroxine administration prevents streptococcal cell wall-induced inflammatory responses. Endocrinology 138(4):1434-1439

Shimazoe T, Shibata S, Yatsugi S, Ueki S (1988): Involvement of the medial amygdaloid nucleus in the action of imipramine in rats subjected to the forced swimming test. J Pharmacobiodyn 11(2):137-139

Solberg LC, Losee-Olsen S, Turek FW, Redei E (in press): Altered hormonal secretions and circadian rhythm of activity in the Wista-Kyoto rat, a putative animal model of depression. Amer J Physiol

Suzuki S, Solberg LC, Redei EE, Handa RJ (in press): Preprothyrotropin releasing hormone 178-199 immunoreactivity is altered in the hypothalamus of the Wistar-Kyoto strain of rat. J Neuroendocrinol

Tizabi Y, Aguilera G, Gilad GM (1992): Age-related reduction in pituitary corticotropin-releasing hormone receptors in two rat strains. Neurobiol Aging 13(2):227-230

van Praag H (1997): Treatment of refractory primary depression. Ned Tijdschr Geneeskd 141:1375-1379

Werka T, Skar J, Ursin H (1978): Exploration and avoidance in rats with lesions in amygdala and piriform cortex. J Comp Physiol Psychol 92(4):672-681

Yamada M, Saga Y, Shibusawa N, Hirato J, Murakami M, Iwasaki T, Hashimoto K, Satoh T, Wakabayashi K, Taketo MM (1997): Tertiary hypothyroidism and hyperglycemia in mice with targeted disruption of the thyrotropin-releasing hormone gene. Proc Natl Acad Sci USA 94:10862-10867

Zangen A, Overstreet DH, Yadid G (1999): Increased catecholamine levels in specific brain regions of a rat model of depression: Normalization by chronic antidepressant treatment. Brain Res 824(2):243-250 